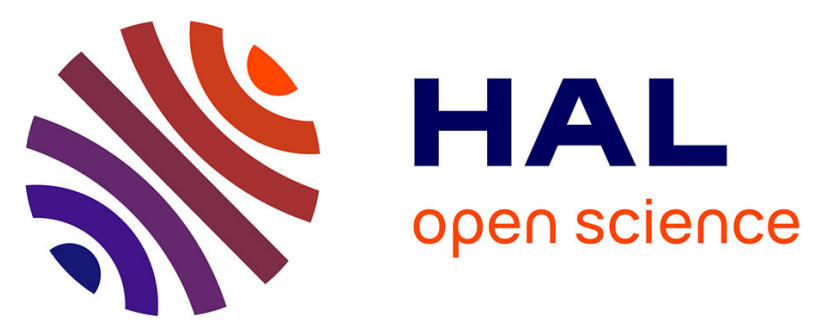

\title{
Experimental characterization and mechanical behaviour modelling of Molybdenum -Titanium Carbide composite for high temperature applications.
}

Cédat Denis, Maximilien Libert, Marion Le Flem, Olivier Fandeur, Colette Rey, Michel Clavel, Jean-Hubert Schmitt

\section{To cite this version:}

Cédat Denis, Maximilien Libert, Marion Le Flem, Olivier Fandeur, Colette Rey, et al.. Experimental characterization and mechanical behaviour modelling of Molybdenum -Titanium Carbide composite for high temperature applications.. International Journal of Refractory Metals and Hard Materials, 2009, 27 (2), pp.267-273. 10.1016/j.jijrmhm.2008.09.018 . hal-00782080

\section{HAL Id: hal-00782080}

https://hal-centralesupelec.archives-ouvertes.fr/hal-00782080

Submitted on 29 Jan 2013

HAL is a multi-disciplinary open access archive for the deposit and dissemination of scientific research documents, whether they are published or not. The documents may come from teaching and research institutions in France or abroad, or from public or private research centers.
L'archive ouverte pluridisciplinaire HAL, est destinée au dépôt et à la diffusion de documents scientifiques de niveau recherche, publiés ou non, émanant des établissements d'enseignement et de recherche français ou étrangers, des laboratoires publics ou privés. 


\title{
Experimental characterization and mechanical behaviour modelling of Molybdenum -Titanium Carbide composite for high temperature applications.
}

\author{
Denis CEDAT ${ }^{\mathrm{a}}$, Maximilien LIBERT ${ }^{\mathrm{a}}$, Marion LE FLEM ${ }^{\mathrm{b}}$, Olivier FANDEUR ${ }^{\mathrm{c}}$, Colette \\ REY $^{\mathrm{a}}$, Michel CLAVEL ${ }^{\mathrm{a}}$, Jean-Hubert SCHMITT ${ }^{\mathrm{a}}$ \\ denis.cedat@ecp.fr, tel : 33 (0) 141131390 , fax : 33 (0) 141131430 \\ ${ }^{a}$ MSSMAT ,Ecole Centrale Paris, 92295 Chatenay Malabry, France \\ ${ }^{\mathrm{b}} \mathrm{CEA}$ DEN/DANS/DMN/SRMA, 91191 Gif-sur-Yvette, France \\ ${ }^{c}$ CEA DEN/DANS/DM2S/SEMT/LM2S, 91191 Gif-sur-Yvette, France
}

\begin{abstract}
Simulations of the elastic-viscoplastic behaviour of ceramic-metal composite, over the temperature range $298-993 \mathrm{~K}$, are performed on realistic aggregates built up from Electron

Back Scatter Diffraction methods. Physical based constitutive models are developed in order to characterize the deformation behaviour of body centered cubic (bcc) metal and face centered cubic (fcc) ceramic under various temperatures. While the ceramic keeps elastic, the viscoplastic behaviour of the metal part is described with a dislocation - based model, implemented in the finite element code ABAQUS, in order to compute local strain and stress fields during compressive tests. It is shown that the adopted constitutive laws are able to give back local complex experimental evidence on weak points of the microstructure.
\end{abstract}

Keywords: Molybdenum, Composite, Thermally activated behaviour

\section{Introduction}

In the scope of refractory materials development for structural applications in the core of the future nuclear reactors such as Gas Fast Reactors, materials combining carbide and refractory metals are of great interest to avoid the major drawbacks of monolithic ceramics (poorly damage tolerant) and metals (neutronic incompatibility). This work focuses on the study of the molybdenum-titanium carbide composite processed by hot isostatic pressing. The investigated material $\left(\mathrm{MoTiC}_{30 \mathrm{vol} . \%}\right)$ was identified as one of the most promising structural materials in term of mechanical strength to operate at temperatures greater than $1000 \mathrm{~K}$ (standard using) and up to $1900 \mathrm{~K}$ (accidental scenario) under a fast neutron flux.

Mechanical studies of Mo-TiC composite have highlighted the need for a knowledge of the properties of the individual components. Thus, this paper consists of relating the microstructure, the behaviour of each phase and the mechanical interactions between the different relevant components to the global behaviour. In this aim, the plasticity mechanisms of molybdenum polycrystal are investigated, carbide being assumed as elastic.

The following work will be concentrated on determining the role of the low/high temperature behaviour in molybdenum, on the composite mechanical behaviour. The concept of thermal activation energy as well as the dislocations interaction mechanisms is used in a modelling taking into consideration the effect of the dislocation density evolution on the flow stress of the deformed material. The understanding of these mechanisms will be investigated through simulation of compressive tests by using a crystalline approach implemented in ABAQUS 
finite element code. Such modellings have shown their efficiency to determine the nondirectly measurable physical mechanisms [1-8]. In this modelling, the determination of material parameters, based on experimental characterization, will be described in this paper.

\section{Materials and experimental procedure}

\section{a) Material Description}

Both titanium carbide $\left(\mathrm{d}_{50}=3 \mu \mathrm{m}\right)$ and molybdenum $\left(\mathrm{d}_{50}=5 \mu \mathrm{m}\right)$ were supplied by $\mathrm{HC}$ Starck. TiC and Mo chemical analysis is given in table 1:

\begin{tabular}{|c|c||c||c||c|c|c||c||c|c|}
\hline \multicolumn{10}{|c|}{ TiC Composition (wt. \%) } \\
\hline \hline $\mathrm{C}_{\text {total }}$ & 0 & $\mathrm{~N}$ & $\mathrm{Ca}$ & $\mathrm{Co}$ & $\mathrm{W}$ & $\mathrm{Ni}$ & $\mathrm{Al}$ & $\mathrm{Fe}$ & $\mathrm{S}$ \\
\hline \hline 19.23 & 0.6126 & 0.0279 & 0.002 & 0.032 & 0.39 & $<4 \mathrm{E}-4$ & 0.0014 & 0.0061 & 0.0019 \\
\hline
\end{tabular}

\begin{tabular}{|c|c|c|c|}
\hline \multicolumn{4}{|c|}{ Mo Composition (wt. \%) } \\
\hline Mo & $\mathrm{O}$ & $\mathrm{Fe}$ & $\mathrm{K}$ \\
\hline 99,8 & 0.0620 & $9 \mathrm{ppm}$ & $29 \mathrm{ppm}$ \\
\hline
\end{tabular}

Table 1: Table of composition of commercial TiC and Mo composition

The composite powder is obtained by milling of $\mathrm{TiC}$ and Mo in alcohol during two hours, with zirconia balls. After alcohol evaporation, the mixing powder is introduced in a latex can and shaped by cold isostatic pressing at 2500 bar during 1 minute. After this step, the green sample is placed in a titanium can and an out gassing in high-vacuum at $600^{\circ} \mathrm{C}$ during 12 hours was carried out. The sintering step is produced by hot isostatic pressing at $1600^{\circ} \mathrm{C}$ during 2 hours under a pressure of $1610 \mathrm{MPa}$. The density obtained is $\mathrm{d}=8,52$ with a total porosity of $1,24 \%$ (isolated porosity $=1,13 \%$ ).

The microstructure of the sintered $\mathrm{Mo} / \mathrm{TiC}$ composite $\left(\mathrm{Mo}-\mathrm{TiC}_{30 \% \mathrm{vol}}\right)$ is referred to a core/shell or core/rim structure with molybdenum as binder phase (fig. 1). 


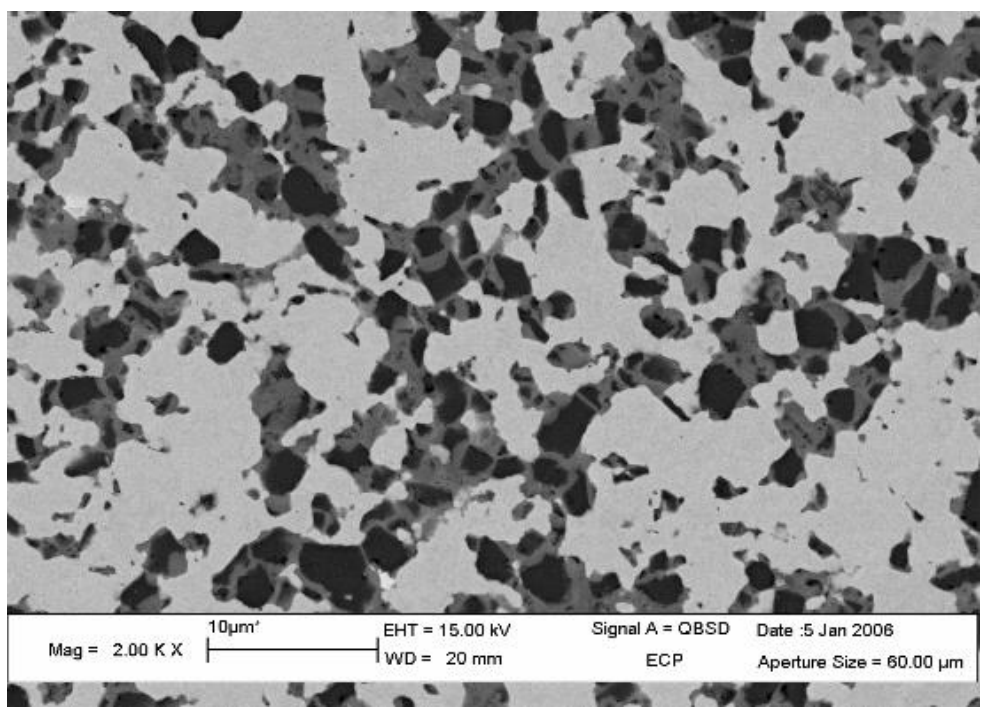

Fig.1: SEM picture showed microstructure in Mo-TiC $30 \%$ vol.

It can be seen that there is titanium carbide core, surrounded by (Mo,Ti)C rim in a molybdenum matrix. The chemical and physical characterizations of this composite [9] have shown that the (Mo,Ti)C phase exhibits a composition close to the solid solubility of molybdenum in the titanium carbide: TiC-Mo ${ }_{10-15 a t . \%}$. It was assumed that (Mo,Ti)C phase, originating from the Mo and TiC powders, is caused by the diffused phases recrystallisation as the shell.

\section{b) Mechanical characterization}

As was mentioned in several studies, plastic deformation is often assumed temperature insensitive. In actual practice, however, the flow stress of ductile bcc metals does show some temperature sensitivity in various ranges of temperature. However this behaviour change couldn't be attributed to brittle/ductile transition which occurs in molybdenum close to $298 \mathrm{~K}$. The molybdenum, in its ductile domain, presents low/high temperature behaviour due to different mechanisms of plasticity.

Strain rates change tests were carried out from $5.10^{-2} \mathrm{~s}^{-1}$ and $5.10^{-4} \mathrm{~s}^{-1}$ at different temperatures on cylinder specimens which were of $12 \mathrm{~mm}$ width and $18 \mathrm{~mm}$ length. The variation of the flow stress with the strain rate is shown in figure 2.a, which shows the stressstrain curved measured at several temperatures added to the strain rate change tests. The figure 2.b shows the stress "jumps" at different strain levels and presents a decrease of stress with the increase of temperature.
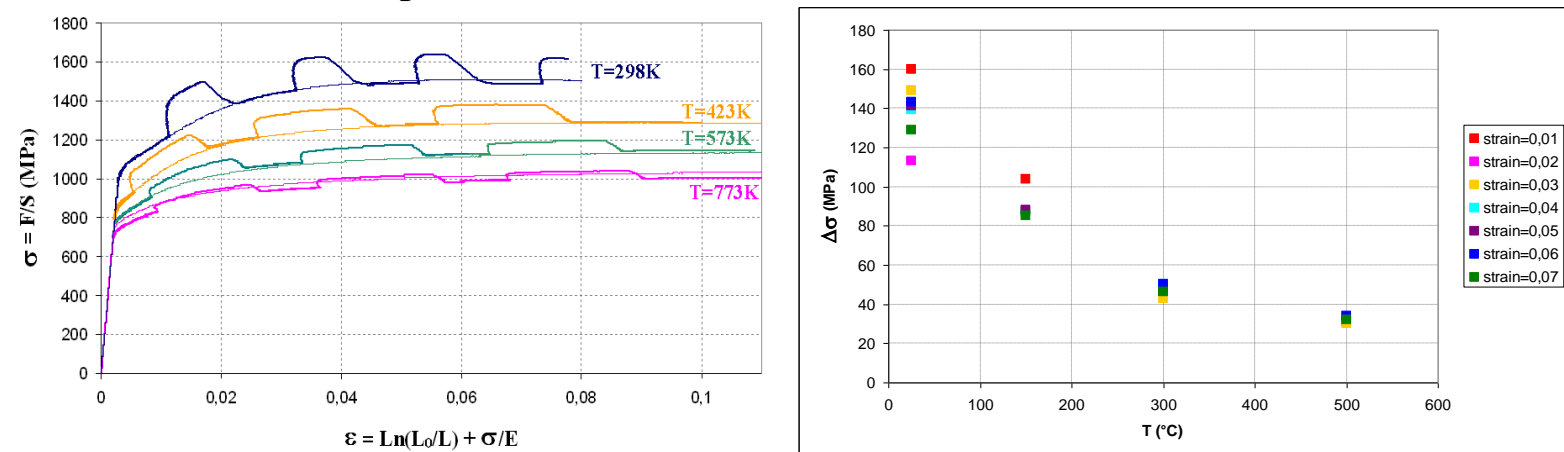

Fig. 2: a) Strain rate change Tests on $\mathrm{MoTiC}_{30 \% \text { vol. }}$ b) Stress jumps vs temperature at different strain levels 
As expected from the results of strain rate change tests, the sensitivity of the flow stress on the deformation temperature decreases. As a matter of fact, an increase in strain rate is equivalent to a decrease in temperature in a thermally activated process.

In fact, the temperature change tests (Fig.3) were realized on same samples shape and give results similar to the strain rate change tests.

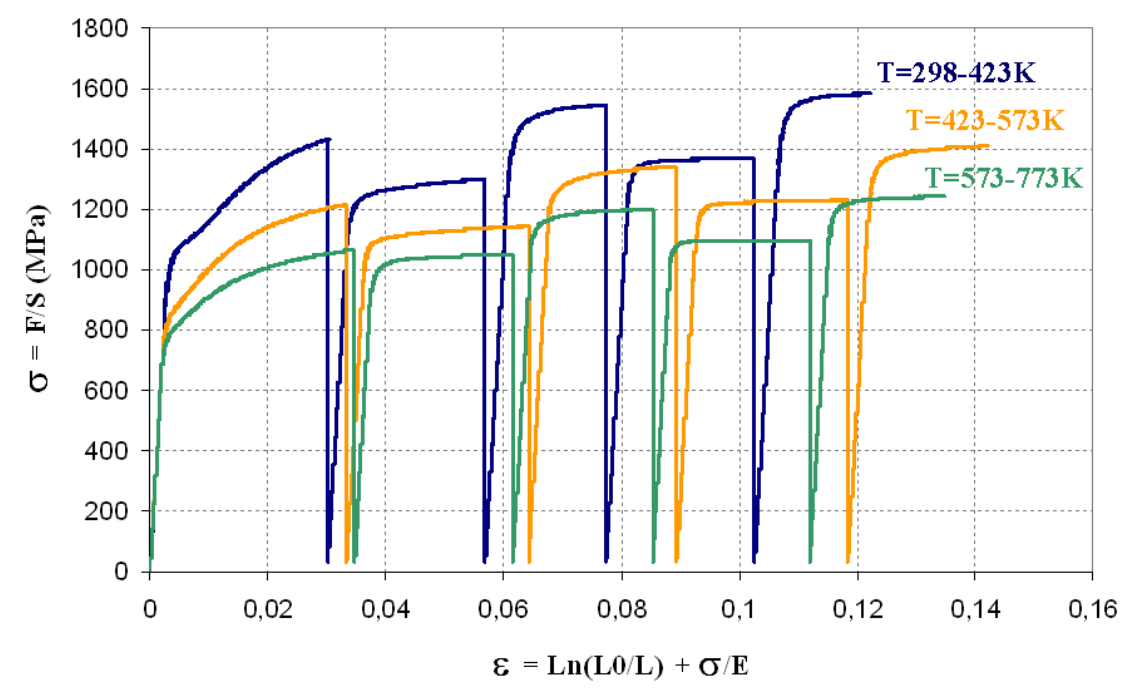

Fig. 3: Temperature change tests on $\mathrm{MoTiC}_{30 \% \text { vol. }}$

Such strain rate sensitivity or, alternatively, temperature sensitivity of the flow stress indicates that the plastic deformation process is thermally activated. By considering the titanium carbide elastic, this thermally activated behaviour of the composite comes from molybdenum properties what it has been investigated on a previous work [10].

\section{Constitutive laws of thermally activated model}

The numerical simulation, undertaken at different scales, predicts the local mechanical fields in the different phases. The used crystalline plasticity model (cristalECP) is developed in the framework of large transformations $[1,11]$ (with small elastic distortion but large lattice rotation) and has been implemented in ABAQUS finite element code, using a User Subroutine UMAT.

Within the framework of the classical theory of thermally activated dislocation motion, a unified constitutive description of the mechanical behaviour of molybdenum is developed. In this paper, a constitutive model is proposed to describe the stress-strain response of commercially pure molybdenum over the temperature range $298-993 \mathrm{~K}$.

\section{a) Constitutive Law}

The model accounts for crystallographic glide and lattice rotation. The mechanisms responsible for viscoplastic flow of molybdenum are essentially the crystallographic slip of two main slip systems $\{110\}<111>$ and $\{112\}<111>$ related to the body centered crystal structure (bcc). By neglecting the slip systems $\{123\}<111>$ in this work, 24 slip systems are considered.

In bcc transition metals, the low-temperature and high-strain-rate plastic deformation properties differ drastically from those of the fcc metals. In particular, there is a rapid increase of flow stress with decreasing temperature and breakdown of Schmid law of critical resolved shear stress. These mechanical behaviour changes are characterized by the temperature of transition $\left(\mathrm{T}_{\mathrm{t}}\right)$ which has been identified around $500 \mathrm{~K}$ in the case of molybdenum. 
Experimental observations suggest that screw dislocations in bcc transition metals are much less mobile than edge dislocations and consequently, screw dislocation slip rate mobility is the limiting factor which controls both low-temperature and high-strain rate plasticity. It is also conceded that a double-kink Peierls barrier mechanism is responsible for the actual mobility of screw dislocations.

Thus the slip rate is controlled by the glide of screw dislocations in the low temperature range (below the temperature $T_{t}$ ). The motion of dislocations is opposed by: (i) short-range barriers due to the lattice friction which can be overcome by thermally assisted formation of double kinks ( $\left.\tau_{\text {eff }}^{s}\right)$, (ii) short-range forces from dislocation forest which can be overcome by athermal shear stress term $\left(\tau_{\text {int }}^{s}\right)$, and (iii) long-range forces due to precipitates $\left(\tau_{0}\right)$. These interactions lead to the following relation:

$$
\tau^{s}=\tau_{0}+\tau_{\text {eff }}^{s}+\tau_{\text {int }}^{s}
$$

Where $\tau_{\text {eff }}^{s}$ is the thermal component of the applied shear stress $\tau^{s}$, associated to the first kind of obstacles, resolved in a slip system (s).

Thus, the chosen viscoplastic law is able to describe the competition between lattice friction and forest hardening. According to Louchet [12], the slip rate on a slip system (s) depends of the mean dislocation velocity, which follows an Arrhenius-type law:

$$
\dot{\gamma}^{s}=\dot{\gamma}_{0} \exp \left[-\frac{\Delta G\left(\tau_{\text {eff }}^{s}\right)}{k_{B} T}\right] \operatorname{signe}\left(\tau^{s}\right)
$$

Where $\tau^{s}, \tau_{\text {eff }}^{s}$ are respectively the shear stress, the effective shear stress on (s), $k_{B}$ is the Boltzmann constant and $T$ the absolute temperature. Indeed, the flow law used is able to account for the overcoming of Peierls valley by double kink mechanism (Fig.5), and specificities of dislocation during double kink mechanism are used as input into the slip rate:

$$
\dot{\gamma}_{0}=2 \rho_{m} v_{D} b^{3} \frac{L^{2}}{l_{c}^{2}}
$$

Where $L$ is the length of the screw dislocation segment (considered as equal to $L_{0}$ according to Louchet), $l_{c}$ the critical length for double kink nucleation, $v_{D}$ is the Debye frequency, $\rho_{m}$ is the density of mobile dislocations whatever their character, and $b$ is the magnitude of the Burgers vector.
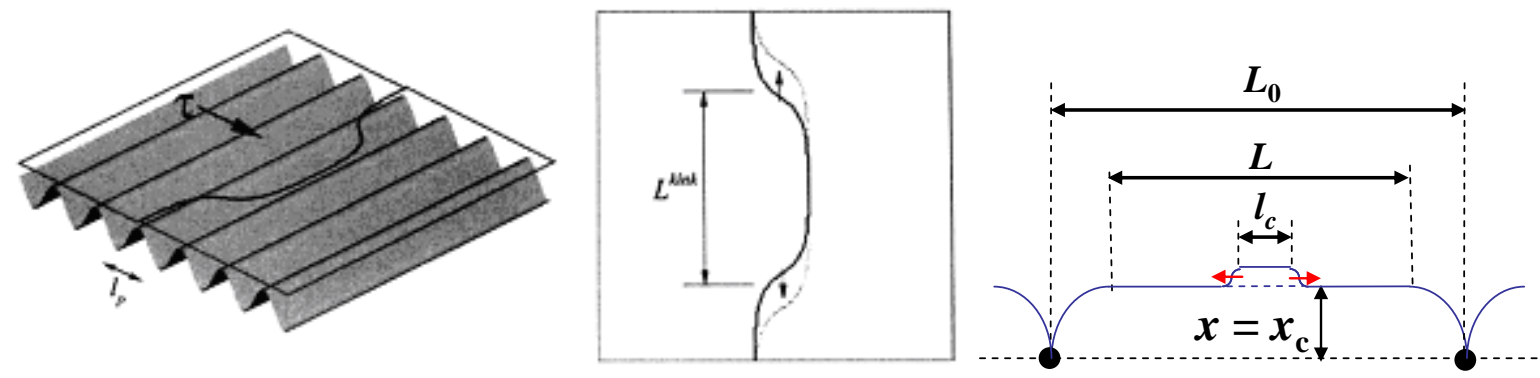

Fig 5: Crossing of the Peierls valley by double kink mechanism

The activation energy is directly connected with the effective shear stress $\tau_{e f f}^{s}$ on the system (s). The effective shear stress is equal to the applied resolved shear stress $\tau^{s}$ deduced from the temperature - independent internal stress $\tau_{\text {int }}^{s}$ due to obstacles.

The phenomenological description, proposed by Kocks and al. [13], described most of the short - range barriers encountered by dislocations as the following profile: 


$$
\Delta G\left(\tau_{\text {eff }}^{s}\right)=\Delta G_{0}\left(1-\left(\frac{\left|\tau_{\text {eff }}^{s}\right|}{\tau_{R}}\right)^{p}\right)^{q}
$$

Where $\Delta G_{0}$ is the activation energy when $\tau_{\text {eff }}^{s}=0, \mathrm{p}$ and $\mathrm{q}$ were parameters describing the shape of the energy profile associated to the Peierls barriers, whereas $\tau_{R}$ is the effective stress to supply in order to create a double kink at $\mathrm{T}=0 \mathrm{~K}$, when the contribution of the thermal activation is strictly useless. The glide of dislocation on a system (s) being active when $\tau_{\text {eff }}^{s}$ is greater than $\tau_{R}$.

\section{b) Hardening law}

The hardening evolution bases on the competition between the lattice friction, which generates a effective stress $\tau_{e f f}^{s}$, and the forest hardening coupled with the crossing of obstacle, for which it is respectively necessary to supply $\tau_{\text {int }}^{s}$ and $\tau_{0}$.

Thus the yield stress required to activate the plastic slip is then equal to the sum of these three contributions (equ. 1).

By considering the dislocation-dislocation interactions on a same system plan (Selfhardening) and the interaction of the system (s) with each of 23 systems (u) potentially latent (Latent-hardening), the internal stress $\tau_{\text {int }}^{s}$ is directly dependent on the local dislocation densities of each system $(s)$ :

$$
\tau_{\text {int }}^{s}=\frac{(\mu b)^{2} \sum_{u} a^{s u} \rho^{u}}{\tau^{s}-\tau_{0}}
$$

Where $\mu$ is the shear modulus and $a^{s u}$ the crystallographic part of the interaction matrix as described by Franciosi [14].

The hardening law, based on the Rauch model [15], translates the competition between lattice friction and forest hardening:

$$
\tau^{s}=\tau_{0}^{s}+\frac{\tau_{e f f}^{s}}{2}+\frac{1}{2} \sqrt{\tau_{e f f}^{s^{2}}+4(\mu b)^{2} \sum_{u} a^{s u} \rho^{u}}
$$

In the restricted strain rate change $\left(5.10^{-2} \mathrm{~s}^{-1}-5.10^{-4} \mathrm{~s}^{-1}\right)$, thermal atomic vibrations assist dislocations to overcome the short-range obstacles at lower values of applied shear stress than that required at $0 \mathrm{~K}$. Under such conditions, an increase in temperature reduces the effective resolved shear stress $\tau_{\text {eff }}^{s}$.

Thus, at temperature below $\mathrm{T}_{\mathrm{t}}$, the forest hardening's contribution appeared as very small compared to effective stress, what leads to:

$$
\tau^{s}=\tau_{0}+\tau_{e f f}^{s}+\frac{(\mu b)^{2} \sum_{u} a^{s u} \rho^{u}}{\tau_{e f f}^{s}}
$$

At temperature above $T_{t}$, there will be sufficient thermal energy for the barriers to be overcome by thermal activation. Then, by considering $\tau_{\text {eff }}\left(T_{t}\right) \approx 0$, the hardening law is thus classically linked to forest hardening in agreement with the well known relation:

$$
\tau^{s}=\tau_{0}+\mu b \sqrt{\sum_{u} a^{s u} \rho^{u}}
$$




\section{c) Dislocation evolution law}

The strain-hardening model takes into account the creation and the annihilation of dislocations through characteristic parameters $\mathrm{K}$ and $\mathrm{g}_{\mathrm{c}}$. This law is a generalisation of the relation proposed by Mecking and Estrin [16]. It describes the evolution of the total dislocation densities rates with strain for each slip system:

$$
\left.\dot{\rho}^{s}=\frac{\left|\dot{\gamma}^{s}\right|}{b} \mid \frac{1}{D_{\text {grain }}}+\frac{\sqrt{\sum_{u \neq s} \rho^{u}}}{K(T)}-g_{c}(T) \rho^{s}\right) \text { with } g_{c}(T)=g_{c 0} \exp \left[-\frac{E_{g c}}{k_{B} T}\right]
$$

Where $\mathrm{K}$ is a material parameter. This equation is derived from the balance between accumulation, based on Orowan's relationship, and annihilation rates.

The annihilation of dislocations is controlled by the main distance $\mathrm{g}_{\mathrm{c}}$, which the temperature dependence was expressed by an Arrhenius law. Thus two dislocations can annihilate together if they interact at a distance smaller than $\mathrm{g}_{\mathrm{c}}$.

\section{4_Determination model constants and comparison with experimental results}

The model, used to describe the mechanical behaviour in molybdenum, brings in many materials constants.

The activation energy values suggest that the thermally activated mechanical behaviour of molybdenum take a real importance in the deformation of the composite, which presents a transition temperature close to $423-573 \mathrm{~K}$. These results will be used in the simulation part to fix the parameter corresponding to the free activation energy $\Delta \mathrm{G}_{0}$.

By considering the carbide as elastic, the thermally activated mechanical behaviour in molybdenum is the main phenomenon which occurs during the deformation of the composite. It turns out essential to implement behaviour laws able to report this phenomenon evolving versus temperature.

To understand the underlying mechanisms in detail, it is, however, necessary to carry out identification of the key parameters at large length scale experiments. For example, the activation energy for double kink motion of screw dislocation has been identified from literature with accurate atomistic simulations on dislocation interaction [17], as well as macroscopic experimental procedures with temperature change tests. Even if most of these parameters could be identified thanks to experimental procedures and bibliography, some of behaviour law coefficients can't be determined by experimental tests. Thus, an inverse method was chosen, using SiDoLo [18,19], to fix these parameters. The resolution of the identification problem consists in minimizing a functional which measures, for a set of given parameters, the distance between the forecasts of the model and the physical reality represented by the experimental observations. The model's parameter evaluation is reduced to the resolution of a problem of non linear optimization.

The molybdenum parameters identified are presented in the table 2:

\begin{tabular}{|c|c|c|c|c|c|c|c|c|c|c|}
\hline$\tau_{0}$ & $\mathrm{a}^{\mathrm{sS}} \mathrm{a}^{\mathrm{su}}$ & $\rho_{0}$ & $\mathrm{~g}_{\mathrm{c} 0}$ & $\mathrm{E}_{\mathrm{gc}}$ & $\mathrm{D}_{\text {grain }}$ & $\tau_{R}$ & $\dot{\gamma}_{0}$ & $\Delta G_{0}$ & $\mathrm{p}$ & $\mathrm{q}$ \\
\hline $70 \mathrm{MPa}$ & 0,01 & $10^{-11} \mathrm{~m}^{-2}$ & $14 \mathrm{~nm}$ & $2,17.10^{-2} \mathrm{eV}$ & $3 \mu \mathrm{m}$ & $498 \mathrm{MPa}$ & $10^{-1}$ & $1,1 \mathrm{eV}$ & 0,2 & 1,5 \\
\hline
\end{tabular}

Table 2: Set of model parameters identified for molybdenum 


\section{Finite element simulation of compressive test}

To constitute the Finite Element mesh, the grid defined by Electron Back Scatter Diffraction measurement is used. Scanning Electron Microscope (SEM) coupled with Electron Back Scatter Diffraction (EBSD) was carried out in order to characterise the microstructure and the orientation of each grain. This aggregate is constituted by several layers chosen to obtain a composition of $\mathrm{MoTiC}_{30 \% \text { vol. }}$ and the texture of the as-received material. However, the layers are not obtained from successive polishing on the same area. Thus, the numerical aggregate built doesn't take into account the real shape of the grain in depth (fig.4).

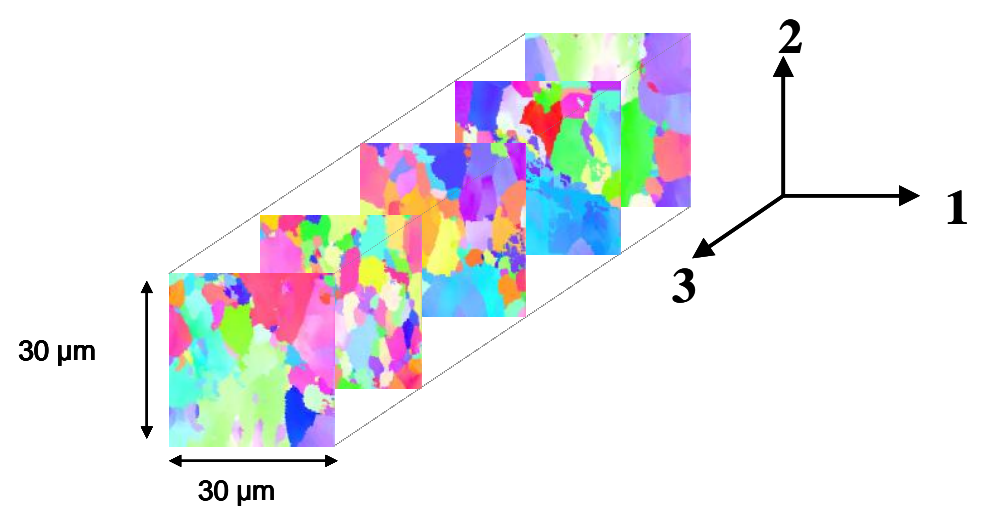

Fig 4: The five EBSD maps used in the numerical aggregate

By this method, geometrical characteristics of the grains and the crystallographic orientations were taken into account in the numerical aggregate which size is about $30 \mathrm{x} 30 \mathrm{x}$ $10 \mu \mathrm{m}^{3}$. The mesh size is $0,3 \mu \mathrm{m}$ and the elements used are C3D8R.

The aggregate is loaded on compression in direction $\mathrm{u}_{2}$. The applied displacement $\mathrm{u}_{2}$ leads to a strain rate of about $5.10^{-4} \mathrm{~s}^{-1}$. The other boundary conditions are $\mathrm{u}_{2}=0$ on the bottom of the aggregate and $\mathrm{u} 3=0$ on the face normal to $\overrightarrow{3}$.

The set of parameters were defined to model the mechanical behaviour in molybdenum and the crystalline approach applied on the numerical aggregate gives the following results (fig.5) on compressive tests performed at different temperatures.

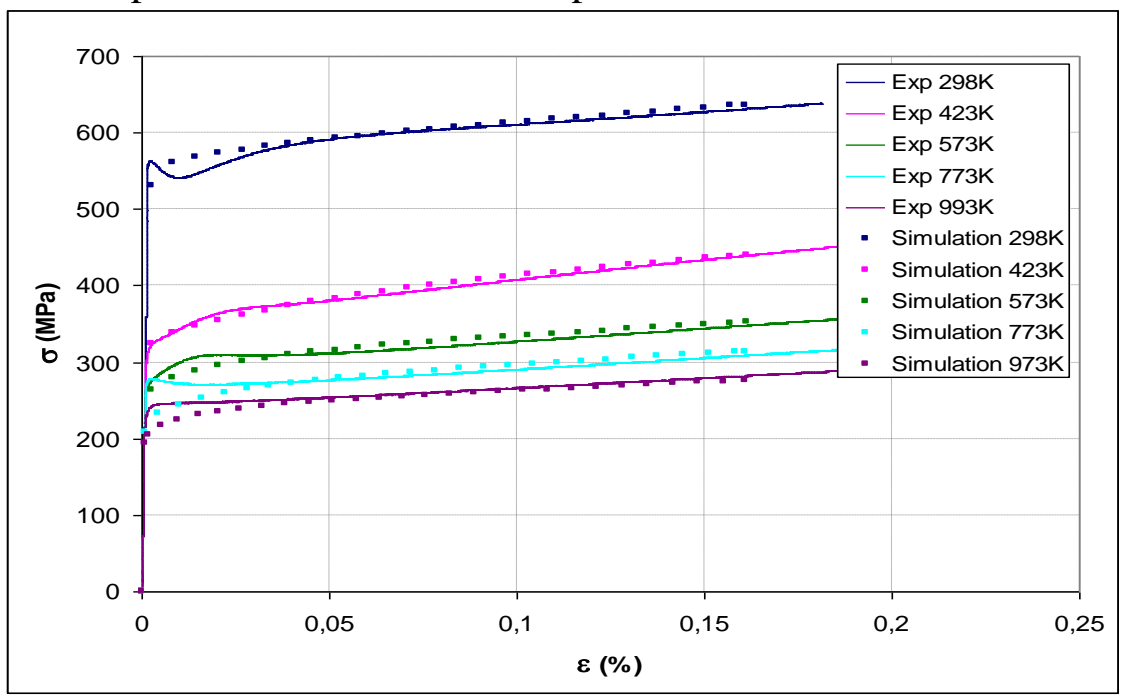

Fig. 5: Experimental and simulated compressive behaviour in molybdenum. 
Figure 6 presents the results of simulation on the numerical aggregate of figure 4 . A large difference can be observed between simulation and experimental test.

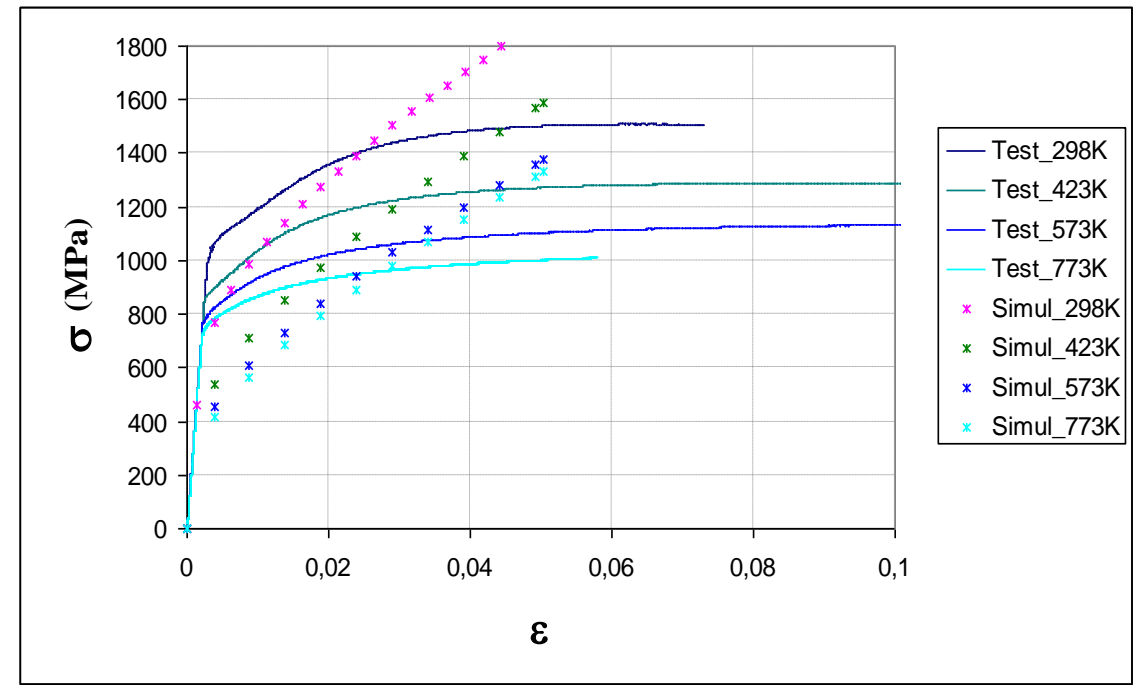

Fig.6: Experimental and simulated compressive behaviour in the composite.

The $\sigma_{\text {mises }}$ values on the map (fig.7) show that a stress concentration takes place in the carbide phase whereas molybdenum accommodates the deformations and experiences large strain level.
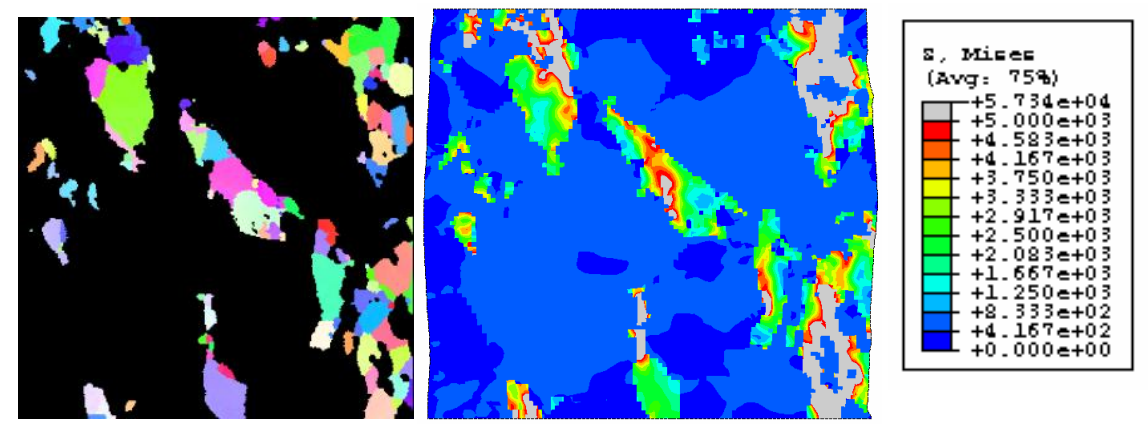

Fig.7: a) EBSD map showing carbide phase on the first layer of the aggregate. b) $\sigma_{\text {mises }}$ (Mpa) map on the first layer of the numerical aggregate in the composite.

\section{Discussion}

The results of the simulation investigated on the composite don't give satisfactory response. Nevertheless, the misfit between computed and experimental compressive curves is assumed to come from to the carbide behaviour. Although, according to the spheres theory, it is intuitively clear that percolation of particles in structure will happen once its concentration reaches a critical value in the system. This critical value is close $33 \%$ in volume what is about the concentration of carbide particles in the composite.

To get a 3D representation of the material, high energy X-ray tomography at the European Synchrotron Radiation Facility (ESRF, Grenoble, France) has been used. This technique basically consists in recording several radiographs of a sample at different angular positions and in reconstructing a 3D map of the X-ray attenuation coefficient within the material using adequate algorithm and software. Fig. 8 illustrates a 3D image of the microstructure of the Mo-TiC material obtained with the highest resolution $(0.28 \mu \mathrm{m})$ available on the ID19 beamline (X-ray energy: $65 \mathrm{keV}$ ) that has been used at ESRF. 


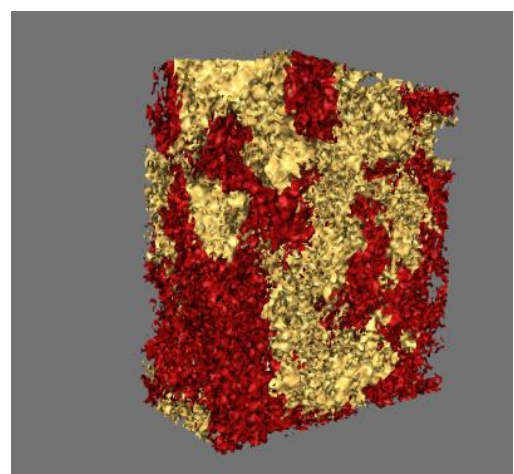

Fig. 8: 3D representation of the composite $(30 \mu \mathrm{m} \times 28 \mu \mathrm{m} \times 14 \mu \mathrm{m})$ interconnected parts of the molybdenum (red) and carbide (yellow) phase.

Fig. 8 represents the set of all points in the carbide phase that can be linked together to the bottom and top faces of the parallelepiped by paths entirely contained in the carbide phase. Consequently, the high 3D connectivity of the carbide phase would be a possible explanation of the observed mechanical behaviour of the composite. In fact, the microstructure of the composite could be seen as a foam of carbide in a matrix of molybdenum.

Thus, the compressive test curve of $\mathrm{MoTiC}_{30 \% \mathrm{vol}}$. at room temperature could be divided in three phases.

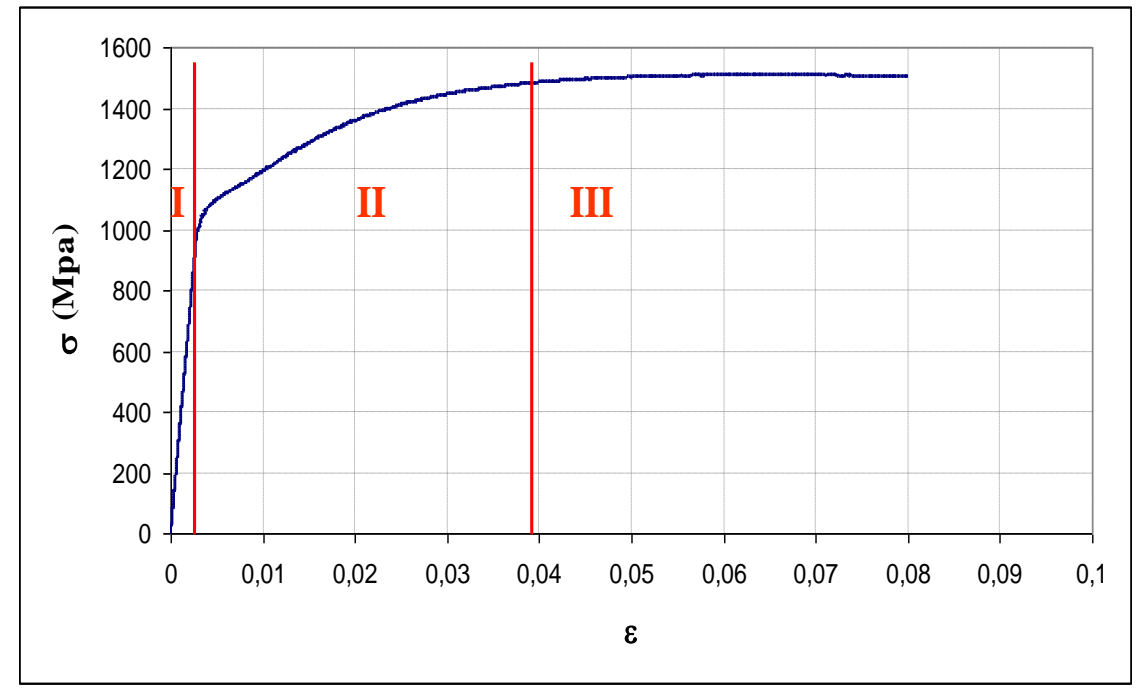

Fig. 9: Stain - stress curve of $\mathrm{MoTiC}_{30 \% \text { vol. }}$ at room temperature.

The first stage corresponds to an elastic deformation of the carbide structure. The second stage starts with the fracture of many titanium carbides' particles which leads to the loss of percolation. At this stage, the microstructure is supposed to be a composite of molybdenum reinforced by $\mathrm{TiC}$ particles. The damage of $\mathrm{TiC}$ occurs all along this stage. The stage III corresponds to the strain-hardening of molybdenum.

As a matter of fact, the aggregate used in simulation doesn't take into account the percolation of the carbide phase what could explain the discrepancy between experimental and simulated results of stress during the transition from the stage I to the stage II. Moreover, the difference of strain-hardening mode would be due to the damage of titanium carbide which is not taken into account in the model. Although, the map on fig. 10 shows that carbide particles are subjected to large tensile stress. 

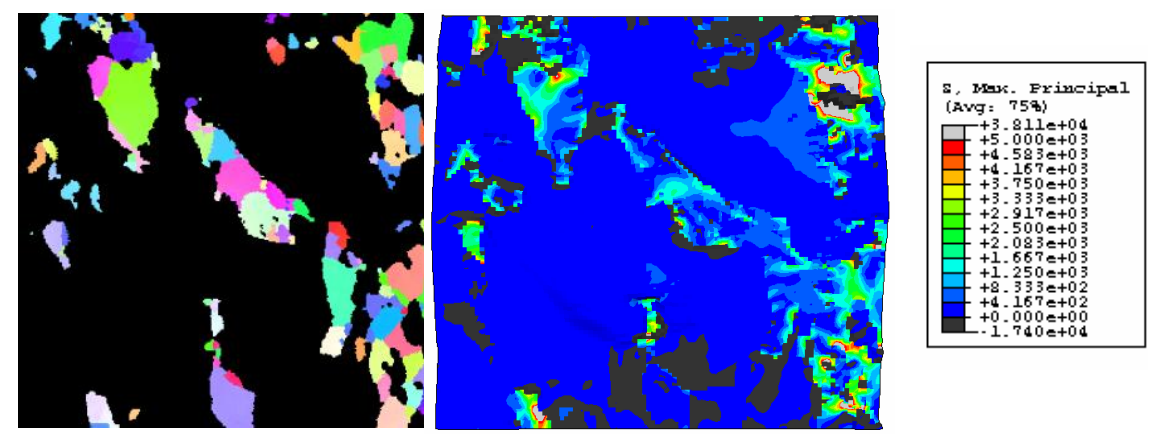

Fig.10: a) EBSD map showing carbide phase on the first layer of the aggregate. $b) \sigma_{\text {princmax }}(M P a)$ map on the first layer of the numerical aggregate in the composite.

The tensile strength of ceramic leading to damage is much less important than compressive strength:

$$
\sigma_{\text {tensile }}=\frac{\sigma_{\text {compressive }}}{15}
$$

Thus, it is assumed that stress component in TiC is sufficiently high to promote premature damage.

\section{Conclusion}

A crystalline plasticity model has been developed in the framework of large transformations to describe the elastic-viscoplastic behaviour of heterogeneous materials. It has been applied to a polycrystalline ceramic/metal composite, and take simultaneously account the plasticity mechanisms through the low/high temperature transition for the viscous part and the elastic behaviour for ceramic. The macroscopic behaviour during compressive tests at various temperatures is successfully simulated for molybdenum. The identification of the model parameters is based on physical and microstructural considerations such as the grain size, the glide of dislocations. Nevertheless, discrepancies between experiments and model exist for the composite. They are attributed to the elastic formulation used which is too restricted to represent the ceramic behaviour.

The proposed assumptions recommend the consideration of the damage and of the percolation in carbide phase. The implemented damage could be reduced by including a plastic yield criterion associated with a critical shear stress. 
[1] Peirce (D.), Asaro (R.J.) and Needleman (A.) - Material rate dependence and localized deformation in crystalline solids. Acta metallurgica, vol n³1, pp. 1951-1976, 1983.

[2] Tabourot (L.), Fivel (M.), Rauch (E.) - Use of mesoscopic simulations to model the dislocations densities evolution law. Proceedings Of the $19^{\text {th }}$ Int. Symposium on Materials Science: Modelling of Structure and Mechanics of Materials from Microscale to Product, 1998, Risø National Laboratory, Roskilde, Denmark.

[3] Bhattacharyya A., El-Danaf E., Kalidindi S. et Doherty R.. - Evolution of grain scale microstructure during large strain simple compression of polycrystalline aluminium with quasi-columnar grains: OIM measurements and numerical simulations. Int. J. Plast., vol. 17, 2001, pp. 861-883.

[4] Hoc T., Rey C., Raphanel J. - Experimental and numerical analysis of localization during sequentials tests for IF-Ti steel. Acta Materalia, 2001, n²49, pp. 1835-1846.

[5] Barbe F., Forest S. and Cailletaud G.. - Intergranular an intragranular behavior of polycrystalline aggregates. part 2 : Results. Int. J. Plast., vol. 17, n 4, 2001, pp. 537-563.

[6] Barbe F., Decker L., Jeulin D. and Cailletaud G.. - Intergranular an intragranular behavior of polycrystalline aggregates. part 1 : F.E. model. Int. J. Plast., vol. 17, n4, 2001, pp. 513536.

[7] Stainier (L.), Cuitino (A.M.) and Ortiz (M.) - A micromechanical model of hardening, rate sensitivity and thermal softening in bcc single crystals - Journal of the Mechanics and Physics of Solids, vol. n ${ }^{\circ}$, pp. 1511-1545, 2002.

[8] Erieau (P.), Rey (C.)- Modelling of deformation and rotation bands and of deformation induced grain boundaries in IF steel aggregate during large plane strain compression. International Journal of Plasticity, vol.n²0, pp. 1763-1788, 2004.

[9] D. Cédat, C.Rey, M. Clavel, J.H. Schmitt, M. Le Flem, A. Allemand, Microstructural characterization of a composite Mo reinforced by $25 \%$ at. TiC, in press, Journal of Nuclear Materials.

[10] D.Cédat, To be published

[11] Teodosiu C., Raphanel J.L. and Tabourot L..- Finite implementation of the large elastoplastic deformation of multicrystals. Large Plastic Deformation, Proc. Int. Seminar MECAMAT'91, ed. pp. 153-168, 1991. [12] Kubin (L.P.), Louchet (F.), Vesely (D.) Description of low-temperature interstitial hardening of the b.c.c. lattice from in situ experiments, Phil. Mag. A, vol. 38, pp205-221, 1978.

[13] Kocks (U. F.), Argon (A.S) et Ashby (M.F.) - Thermodynamics and kinetics of slipProgress in Materials Science, vol 19. Pergamon Press Oxford, 1975.

[14] P. Franciosi , Glide mechanisms in bcc crystals: an investigation of the case of $\alpha$-iron through multislip and latent hardening tests, Acta metall. , 31 (1983), 1331-1342.

[15] Rauch (E.) - Etude de l'écrouissage des métaux, aspects microstructuraux et lois de comportement, thèse de HDR, Institut National Polytechnique de Grenoble, 1993.

[16] Estrin (Y.), Mecking (H.) - A unified phenomenological description of work hardening and creep based on one-parameter models- Acta metallurgica, Vol 32, №1, pp. 57-70, 1984. [17] Xu (W.), Moriarty (J.A.) - Accurate atomistic simulations of the Peierls barrier and kinkpair formation energy for $\{111\}$ screw dislocations in bcc Mo, Computational Materials Science, July 1997

[18] Pilvin P. - SiDoLo version 2.4, Notice d'utilisation. Rapport Technique, Ecole Centrale Paris, 1998.

[19] Cailletaud G., Pilvin P. - Identification and inverse problems related to material behaviour. Proceedings of the International Seminar on Inverse problems, Clamart, pp. 79-86, 1994. 